\title{
Local perspectives and global archetypes in scenario development
}

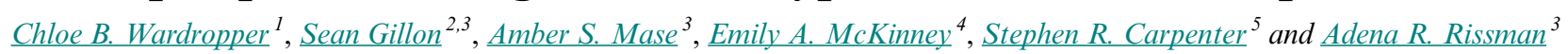

\begin{abstract}
Contrasting social-ecological scenarios can help stakeholders envision potential futures and navigate change and uncertainty. Scenario developers integrate stakeholder perceptions into storylines to increase scenario relevance and plausibility while relying on archetypes of change from scenario literature to enrich narratives. This research examines the contributions of local perspectives and global archetypes to scenario development through a case study of a regional scenario project, Yahara 2070, in Wisconsin, USA. Interviews with 50 Yahara watershed stakeholders and 5 members of the project's scenario development team were examined to compare themes from scenario archetypes with local perspectives on how change is expected to occur. We next examined how these two sources of inspiration for trajectories of change were used in the development of the Yahara 2070 scenarios. Both global archetypes and local stakeholders emphasized social values, market forces, and policy reform as influences in determining the future, which were reflected in Yahara 2070. However, stakeholders were less likely to mention institutional breakdown, an important theme from the global scenarios literature that was included in Yahara 2070. This research offers a new approach to analyzing similarities and differences between scenarios' narratives and local perspectives. Scenario development may involve tensions between the goals of reflecting stakeholder views and including narratives from the global scenarios literature that may be useful for creating divergent model trajectories and addressing dramatic change into the future. To improve scenario development, scenario projects should document the development process in academic and nonacademic venues, explicitly highlighting sources and constraints in storyline development.
\end{abstract}

Key Words: scenario archetypes; scenario development; social and environmental change; stakeholder perspectives; watershed futures

\section{INTRODUCTION}

Climate, hydrologic cycles, and landscapes are changing rapidly. Societies and organizations must adapt in response to current change and anticipated futures. Scenarios of future socialecological change have the potential to engage relevant social groups in envisioning plausible futures and considering pathways for decision making under uncertainty (Carpenter et al. 2006). We define scenarios as "plausible descriptions of how the future may develop, based on a coherent and internally consistent set of assumptions about key relationships and driving forces," such as changes in markets or social values (Millennium Ecosystem Assessment 2003:214). Scenarios are meant to identify key themes and driving forces in stakeholders' concerns for the future to construct divergent stories that can guide decisions, rather than predict the "right" version of the future (Wack 1985). Scenarios projects that integrate qualitative stories with quantitative modeling also serve to organize research efforts based on trajectories of potential future change, using varied socioeconomic, landscape, and climate drivers.

As scenarios become more widely used and recognized through projects such as the International Panel on Climate Change and Millennium Ecosystem Assessment scenarios, the ways in which scenarios influence society through changes in stakeholders' interests, knowledge, risk perceptions, or beliefs about particular issues have come under increased scrutiny by social scientists (Garb et al. 2008, Pulver and VanDeveer 2009). Likewise, the process of scenario development also deserves attention (Garb et al. 2008). Scenario developers, defined here as those involved in writing narratives that describe plausible futures, visually illustrating them, and linking the storylines to quantitative models, face the challenge of how to construct narratives of future change and what data or inputs to use. Despite calls to make scenario planning accessible to a wide audience (Millett 2003, Carpenter and Rissman 2012), scenario development is often a "black box" to observers outside the research team. Although the methods are described in publications, narrative influences that shape the construction of divergent scenarios are often not transparent to the public. In business literature (Schwartz 1996, Van der Heijden 2011), government publications (e.g., National Park Service 2013), and other applied literature (e.g., Evans et al. 2006), scenario practitioners offer detailed descriptions of scenario development. However, influences on scenario narrative development are given little attention in peer-reviewed literature (although for exceptions, see Alcamo 2008 and van Vliet et al. 2012). Better understanding of how narratives are constructed from different data sources and how those narratives interface with other aspects of a scenario project would likely improve scenarios' applicability and assessment.

The primary objective of this research was to develop a new approach to examining multiple influences on scenario narrative development, including stakeholder perspectives, academic literature, and modeling requirements, through a case study of a Midwestern, USA, watershed integrated scenarios project, Yahara 2070 (https://wsc.limnology.wisc.edu/yahara2070; Carpenter et al. 2015a). Yahara 2070 follows a long tradition of local and regional scenarios of social-ecological change (Peterson et al. 2003, Enfors et al. 2008, Palomo et al. 2011, Palacios-Agundez et al. 2013). Developers of local and regional watershed scenarios around the world use a variety of methods (March et al. 2012); Yahara 2070 development combined stakeholder engagement, through interviews and workshops, with review of news stories, science fiction, and global scenario archetypes (e.g., Hunt et al.

\footnotetext{
${ }^{1}$ Nelson Institute for Environmental Studies, University of Wisconsin-Madison, ${ }^{2}$ Department of Food Systems and Society, Marylhurst University, ${ }^{3}$ Department of Forest and Wildlife Ecology, University of Wisconsin-Madison, ${ }^{4}$ Department of Sociology, University of Wisconsin-Madison, ${ }^{5}$ Center for Limnology, University of Wisconsin-Madison
} 
2012, Van Vuuren et al. 2012). The resulting scenarios and accompanying model outputs were intended to offer a range of plausible futures and incite conversation.

To better understand scenario development processes and outputs, we compared local participant perspectives on change derived from prescenario development stakeholder interviews (n $=50$ ) with six themes of change from scenarios archetypes (Hunt et al. 2012) and the resulting Yahara 2070 scenarios. This analysis is focused on two primary research questions: (1) How do the Yahara 2070 narratives integrate local stakeholder perspectives with themes common in the global scenarios literature? (2) How did Yahara 2070 scenario developers navigate multiple data sources, analytical modes, and project objectives and constraints to create scenarios of future change? The following sections provide background on goals for scenario development and common sources of data or inspiration and decision points for scenario developers.

The choice of which themes of change to include in scenario narratives depends on development goals. Yahara 2070 developers aimed to create scenarios that were plausible and provocative. Plausibility, defined as the quality of being "believable or realistic" (Merriam-Webster 2004), was a key criterion for advancing narratives as feasible, realistic, and based on evidence about what could occur (Wiek and Iwaniec 2014). The developers also wanted the scenarios to be provocative, defined as "causing discussion, thought, argument" (MerriamWebster 2004), to introduce new ideas and illuminate dramatic potential changes to spark conversation and allow for divergent model outcomes (Chermack et al. 2001, Peterson et al. 2003). Engaging both regional and global drivers of change was also identified as an important scenario development criterion to increase Yahara 2070 scenarios' international relevance and consider dynamics of change at multiple scales. To create provocative storylines, Yahara 2070 scenario developers made certain top-down decisions about the inclusion of narrative themes not brought up by stakeholders.

We expected the Yahara 2070 scenarios' themes to diverge from local stakeholders' perspectives on change, because the project goals included engendering provocative stories, fostering creative conversations, and provoking discussion or even debate about what the future may bring to this region (Smith 2002, Carpenter et al. 2006). We further expected to see differences among stakeholder responses by gender. Studies in the literature on perceptions of risk suggest that "men tend to judge risks as smaller and less problematic than do women" (Slovic 1999:692), and women may create more vivid imagery than men when they worry (Loewenstein et al. 2001). Sundblad et al. (2007) found that women worry more about climate change than men, accounting for education level and knowledge of climate change. We wanted to know whether these differences were reflected in which themes of change women and men perceived as important for the future. We also anticipated stakeholder differences based on their affiliation with the agricultural industry; because the Yahara has distinct urban and rural regions, those living or working in rural agricultural areas were expected to frame environmental issues differently than those in the city or suburbs (O'Neill 2007, Gillon et al. 2016).

\section{Developing scenarios using themes from the global scenarios literature and stakeholder perspectives}

Scenario developers have a wealth of narrative inspiration to draw upon, including literature on existing scenario projects (de Vries and Petersen 2009, Metzger et al. 2010) and local stakeholder perspectives (Kok and van Vliet 2011). This analysis examines and evaluates the process of connecting themes of change from scenarios literature and stakeholder perspectives to regional scenario development. With a "story and simulation" approach, model simulations capture system attributes that can be parameterized, such as climatic response to atmospheric greenhouse gas concentration, and storylines fill out the picture with more complicated or contextual future changes such as human values shifts (Lempert 2013). Modelers generally develop quantitative trajectories for climate, land use, human population, and other variables based on the qualitative narratives, in addition to incorporating information from climate and demographic models and understandings of system dynamics. Thus, scenario narratives must depict a range of events to be modeled, from floods and droughts to introductions of invasive species, new technologies, or policies. The usability of modeling outputs can be greatly improved when they are manipulated to represent divergent ecosystem outcomes that are relevant to policy makers and citizens (Jacobs et al. 2010, Kepner et al. 2012).

Common themes of change, from values shifts to technological innovation to business as usual, are influential for scenario developers working on local or global scales. The interdisciplinary Global Scenario Group (GSG) proposed a set of plausible, divergent world end states for scenarios based on an analysis of previously developed social-ecological scenarios, mostly at the global scale (Hunt et al. 2012). Their synthesis of scenarios resulted in three primary archetypes of change: Conventional, Great Transitions, and Barbarization. We focused on two primary themes, or main ideas about what drives or results from change, for each of these three primary archetypes. Conventional change themes included Markets, in which actors advance growth, liberalization, and privatization; and Policy, in which government action drives sustainable development. Great Transitions themes included Social Values change, promoting broad-based socialecological stewardship; and Localism, in which local self-reliance in rule making and economic growth drives change. Themes from the Barbarization archetypes were Inequity, in which authoritarian rule divides haves and have-nots; and Collapse, in which conflict creates institutional collapse, which drives further change. We use these six themes (Markets, Policy, Social Values, Localism, Inequity, and Collapse) to represent commonly used pathways of change in global scenarios projects (Table 1). Although other reviews of scenarios (Van Vuuren et al. 2012, Oteros-Rozas et al. 2015) have suggested additional scenario categories, we reference the themes from the Hunt et al. 2012 review because they were most influential to the Yahara 2070 scenario development process due to their focus on storylines and commitment to including cross-scale drivers of change.

Incorporating themes from global scenarios archetypes into local efforts can broaden the range of change narratives, based on what has been experienced or dreamed up in different parts of the world, forging connections between local and global conversations (Biggs et al. 2007, Carpenter et al. 2015a). Although scenarios are often developed for a particular spatial extent, i.e., 
local (e.g., a neighborhood), regional (e.g., subnational, national, or continental), or global, studies of complex systems have called for better analyses of processes and interactions across scales (Gibson et al. 2000, Walker et al. 2006). Some explicitly multiscalar scenarios (Biggs et al. 2007, Kok et al. 2007) offer the opportunity to more dynamically consider different perspectives, vulnerabilities, and the potential for change. Scenarios' widely varying timescales also lead to different types of conversations, from immediate decision-making applications to visionary planning (van Notten et al. 2003). Local and regional scenarios tend to downscale change drivers, such as climate change, and may focus on sectors of interest to the project, such as agriculture (e.g., Rounsevell et al. 2005) or water (e.g., March et al. 2012). However, many scenario projects, even at a local or regional scale, use change themes from the global literature for inspiration to describe potential pathways of social and landscape transformation (Zurek and Henrichs 2007, Rounsevell and Metzger 2010).

Table 1. Scenario archetypes, change themes, and keyword descriptors. Adapted from Hunt et al. (2012).

\begin{tabular}{|c|c|c|}
\hline Scenario archetype & $\begin{array}{l}\text { Change } \\
\text { themes }\end{array}$ & Keywords \\
\hline $\begin{array}{l}\text { Conventional } \\
\text { Currently dominant driving } \\
\text { forces, i.e., the economy } \\
\text { and government, shape } \\
\text { social-ecological conditions }\end{array}$ & Markets & $\begin{array}{l}\text { Economy, market, } \\
\text { deregulation, private } \\
\text { business, consumerism } \\
\text { Government, politicians, } \\
\text { policy, regulation, the state, } \\
\text { or the public sphere }\end{array}$ \\
\hline
\end{tabular}

Great Transitions Novel value systems and approaches to development and decision making emerge

Social values Social values, social leaders, and people (individuals and groups)

Localism Grassroots and local activities, autonomy at a small scale, and decentralization

\section{Barbarization}

Society succumbs to

fragmentation, collapse, and institutional failure

$\begin{array}{ll}\text { Inequality } & \begin{array}{l}\text { Poverty, immense } \\ \text { inequality, authoritarian } \\ \text { rule or power in the hands } \\ \text { of a few, or military control } \\ \text { of natural resources }\end{array} \\ \text { Collapse } & \begin{array}{l}\text { War, violence, and the } \\ \text { collapse of civil order }\end{array}\end{array}$

In addition to scenarios literature, another important source of inspiration for scenarios development is a participatory process in which developers gather and utilize input from a range of stakeholders on potential pathways of change (Biggs et al. 2007). Stakeholders typically include policy makers, business leaders, nonprofit organizations, and other citizens working and living in the region or on the issues relevant to the scenarios. Developers can rank public preferences on different scenarios and their impacts (Van Huylenbroeck 1995), or interest groups may identify the goals, ecosystem services, and policies that define future narratives (Bohensky et al. 2006). Community input on landscape and social conditions can define key issues and perceived future threats, as well as identify the potential end points of change pathways (Patel et al. 2007, Kok et al. 2011). Local stakeholders' perceptions of change pathways and world end states may mirror those represented in commonly used global scenario archetypes, but this may not always be the case. The authors found no research specifically dealing with whether stakeholder perceptions of change incorporate or do not incorporate common archetypes of change, and the relative weights given to stakeholder-driven versus archetype-driven storylines in scenario construction (with the exception of the gray literature, e.g., PBL 2004). This balance may have implications for whether scenarios allow both academics and nonacademics to explore uncertain futures through quantitative models and creative dialogue.

\section{STUDY METHODS}

\section{Study area: Yahara Watershed, Wisconsin, USA}

This analysis draws on Yahara 2070 scenario development efforts. "Yahara" refers to the Yahara watershed of southern Wisconsin, USA, which drains 1345 square kilometers and is home to a population of 372,000 . The watershed includes five major lakes (Mendota, Monona, Wingra, Waubesa, Kegonsa), iconic water bodies that are used extensively for recreation and have been called the most studied lakes in the world (Lathrop 2007). Yahara is a largely agricultural watershed producing corn, soy, and dairy that contains a densely populated urban and suburban center, Wisconsin's state capital of Madison (Fig. 1). In addition to agriculture, the local economy includes some industry, state government, and the large state university system.

Fig. 1. Map of the Yahara River watershed (Wisconsin, USA) and the land use/land-cover pattern (with percent cover) for 2011, derived from National Land Cover Data. Delineations of the Yahara watershed were based on light detection and ranging (LiDAR) elevation, sewer-sheds from the city of Madison, and a field-checked basin map from Dane County, Wisconsin. Two aerial photos in the upper-right corner were taken in summer 2013 and illustrate the typical agricultural landscape (top) and acceleration of urbanization (bottom) in this watershed. Reprinted from Carpenter et al. 2015a.

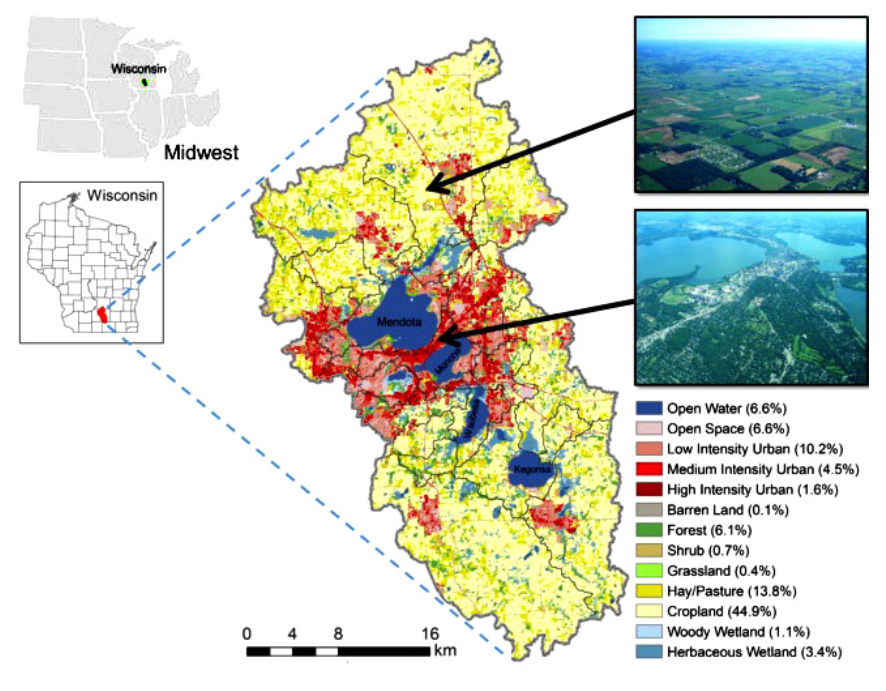


Yahara's freshwater quality has deteriorated over the past century because of excessive phosphorus inputs from sewage discharges, fertilizer and manure application, and agricultural and urban runoff (Lathrop 2007). Over the last 50 years, public and private organizations, including state and local agencies, nonprofit organizations, and grassroots watershed groups, have worked to address eutrophication through management actions including storm water management, agricultural nutrient management, and wetland restoration, although reducing nonpoint source pollution has proved extremely challenging (Carpenter et al. 2007, Rissman and Carpenter 2015, Gillon et al. 2016). Public policy intervention is carried out in the context of the United States' federalist system, in which all levels of government, federal, state, county, and municipal, reduce erosion and nutrient runoff through a variety of strategies, including incentives, regulations, land acquisitions, and direct management practices (Wardropper et al. 2015).

Changing trends in climate, hydrology, and land use, among other processes, increasingly threaten Yahara lake water quality through increased heavy rainfall events (Motew and Kucharik 2013, Carpenter et al. 2015b, Gillon et al. 2016), altered plant phenology (Bradley et al. 1999), and introductions of invasive species (Carpenter et al. 2007). Given the uncertainty of these trajectories into the future, the goals of Yahara 2070 scenario development were to foster creative conversations, enhance capacity to address change under uncertainty, and direct quantitative models of the watershed's ecosystem services (Carpenter et al. 2015a). Yahara 2070 is a story and simulation project in which the four scenarios, i.e., Abandonment and Renewal, Accelerated Innovation, Connected Communities, and Nested Watersheds (Fig. 2), will be simulated through integrated models. Yahara 2070 models are based on the scenario narratives and respond to driver curves that are numerical trajectories of change in land use categories (e.g., urban, corn, forest) and climate indicators (e.g., average annual temperature, number of heavy rainfall events, length of growing season) from the present to 2070 for each scenario. The suite of models used for the project includes Agro-IBIS, which simulates terrestrial ecosystem processes; MODFLOW, a groundwater flow model; THMB (Terrestrial Hydrology and Biogeochemistry Model); and YWQM (Yahara Water Quality Model; see Carpenter et al. 2015a for further explanation of model development and use).

\section{Stakeholder input}

Analysis for the first research question (How do the Yahara 2070 narratives integrate local stakeholder perspectives with themes of change common in global scenarios literature?) drew on qualitative data collected during scenario development processes. The Yahara 2070 team conducted interviews with 50 local stakeholders in June through December 2011 to gather opinions on desirable future states and drivers of future change. The team also conducted four workshops from October 2011 to February 2012 with a total of 51 attendees to elicit initial reactions to draft storylines; however, workshop results are not analyzed here. Interview and workshop participants were asked to participate based on their roles as leaders and opinion makers in the watershed. Contacts were made using existing researcher connections and snowball sampling (Huberman and Miles 2002). The resulting group was composed of 17 females and 33 males with an array of professional and volunteer affiliations: 18 from the government sector, 10 in research positions, 10 from the business sector, and 12 affiliated with nongovernmental organizations. Of the participants, 9 had an agricultural affiliation, as farmers or farm conservation professionals, and 35 had a natural resources affiliation. Most stakeholders held leadership roles in their organizations. All interviews were conducted by one of two project members using a semistructured format. Interviews were recorded and transcribed. The interview data provided insights into each individual's social, cultural, economic, and environmental values and understandings or imaginings of how regional change might occur.

Fig. 2. Yahara 2070 scenarios. See https://wsc.limnology.wisc. edu/yahara2070 to learn more.

What would life in the Yahara Watershed in 2070 be like if...

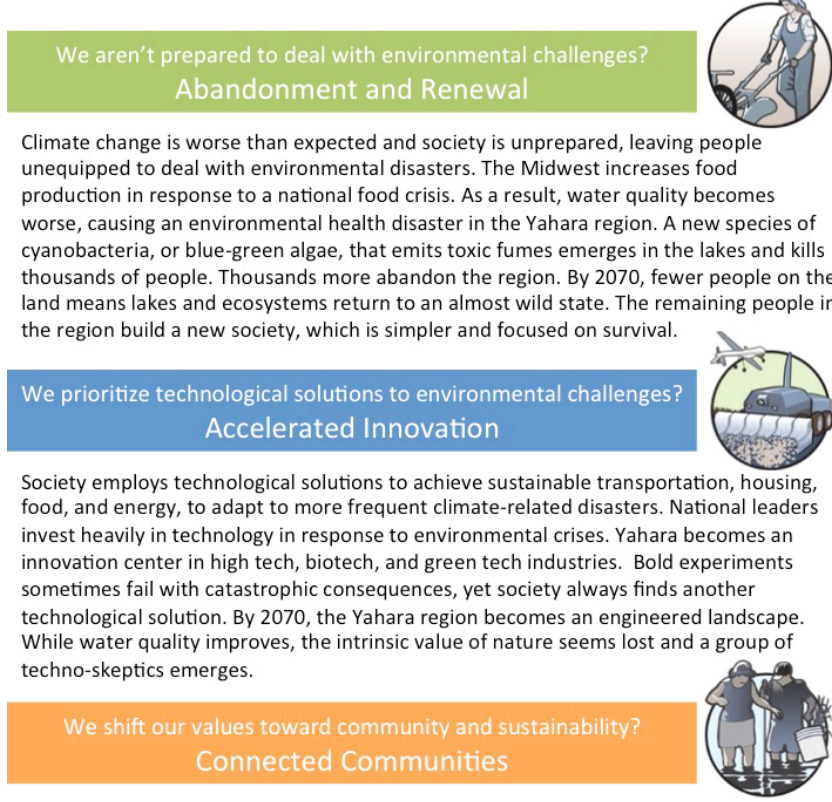

Looming environmental crises incite a global movement to adopt sustainable values and behaviors. Sustainability and community become central to decision making. Sustainable transportation, housing, food, and energy become the norm. Life becomes oriented around community well-being and away from material consumption. Some conveniences, such as cheap air travel are lost. By 2070, the Yahara region is a mosaic of sustainable agricultural, urban, and natural areas, with healthier land and slowly improving water quality. The climate gradually stabilizes, but remains altered.

\section{We transform the way we govern water to better protect it?} Nested Watersheds

Climate change is worse than expected and the nation faces a freshwater crisis. The public demands solutions from the government. Authorities in the Yahara region incentivize and regulate practices to ensure a clean and sufficient supply of freshwater, resulting in massive changes in land use. By 2070, water is considered the region's key resource and is managed more holistically on the watershed scale, rather than along political boundaries. However, the adaptive measures are mostly small and climate change has still not been adequately addressed.

We analyzed the 50 interview transcripts to determine perspectives on future change. We coded responses to the interview question, "Who or what will be most influential in determining the future?" using the qualitative analysis software Dedoose. We identified mentions of change themes corresponding to one of the six global scenarios archetypes, 
Table 2. Scenario change themes, with illustrative interview excerpts, and primary Yahara 2070 scenario associated with each theme.

\begin{tabular}{|c|c|c|}
\hline Change theme & Illustrative stakeholder quote & $\begin{array}{l}\text { Yahara } 2070 \text { primary } \\
\text { scenario }\end{array}$ \\
\hline \multicolumn{3}{|l|}{ Conventional } \\
\hline Markets & $\begin{array}{l}\text { I'm an accountant, so I gotta say it's economics. I really do. It's people's well-being. That has an } \\
\text { impact on development. It has an impact on politics. It has an impact on health. It has an impact on } \\
\text { social services. }\end{array}$ & Accelerated Innovation \\
\hline Policy & $\begin{array}{l}\text { I do believe who is ultimately, politically in charge of the state and of the county is a huge factor... Our } \\
\text { political leaders, and that includes our governor, that includes our president of the United States, they } \\
\text { need to continue to prioritize it and let it filter down to us and then tell us, "This is what you're going } \\
\text { to prioritize yourself." }\end{array}$ & Nested Watersheds \\
\hline \multicolumn{3}{|l|}{ Great Transitions } \\
\hline Social Values & $\begin{array}{l}\text { I think at the end of the day, it's people. It's people who live in those communities. I think that you can } \\
\text { have meaningful and well-intended researchers doing work in their area. You may have good } \\
\text { politicians trying to pursue good policies. But if the people from those neighborhoods, those } \\
\text { communities, are not engaged, you don't get anywhere. So I think it's about reengaging the community } \\
\text { in the issues that matter to them. }\end{array}$ & Connected Communities \\
\hline Localism & $\begin{array}{l}\text { We have to empower locals to do what they feel is necessary and sustainable. I think that's first. It's } \\
\text { gotta be a locally led effort. }\end{array}$ & [None] \\
\hline \multicolumn{3}{|l|}{ Barbarization } \\
\hline Inequality & $\begin{array}{l}\text { Those that control energy and food... influence the market. Or maybe it's something a little bit more } \\
\text { nefarious and they have a lot of political influence, whether it is campaign contributions or whatever. } \\
\text { That's typically how I view the world today in a lot of how policy is created. It's these companies that } \\
\text { control energy and food. }\end{array}$ & [None] \\
\hline Collapse & $\begin{array}{l}\text { I think one of the things that can be most powerful is these moments of crisis. The outbreaks of a huge } \\
\text { disease, outbreak of some kind of insect that-despite all of our entomologists-that kills corn plants } \\
\text { or kills soybeans off and we can't do anything about it. }\end{array}$ & $\begin{array}{l}\text { Abandonment and } \\
\text { Renewal }\end{array}$ \\
\hline
\end{tabular}

adapted from the categories described by Hunt et al. in 2012 (Tables 1 and 2). A 3-point scale was used to weight mentions of themes within interviews. A 3 was assigned when themes were mentioned with strong qualifiers such as "dominant" or "key," and/or were discussed extensively by the respondent. At the low end, a 1 was assigned when themes were mentioned in conjunction with weak qualifiers such as "could" or "I guess," were mentioned late in the response, or were mentioned very briefly. A Wilcoxon signed-rank test (the nonparametric form of the paired samples $t$ test) assessed the differences in means of the six theme weightings for interviewees who mentioned more than one archetype and was calculated in STATA version 13 (StataCorp, College Station,

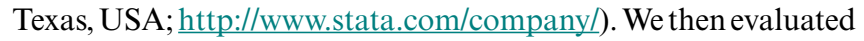
the weightings by interviewee descriptors. We used Pearson's chisquared tests to evaluate the likelihood of differences between the categorical variables across three descriptors of interest: interviewees' affiliation with natural resource organizations, affiliation with agricultural organizations, and gender. Only differences in the latter two groups were significant, so discussion of analysis by natural resources affiliation is not included in this analysis.

\section{Global archetypes and local perspectives in Yahara 2070 scenarios}

We compared the relative importance of the six change themes in the global literature, in Yahara 2070, and among the Yahara stakeholders. We analyzed each of the final Yahara 2070 narratives, unveiled to the public in May 2014, for themes drawn from Hunt et al.'s (2012) six GSG categories. We coded mentions and weighted the importance of themes for each. A theme was recorded as primary for interviewees and scenarios if it was the only theme assigned a " 3 " weight for that person or scenario.
We then used a review of scenario-based studies from 1997 to 2011 by Hunt et al. (2012) to determine the approximate percentage of global scenarios projects that used storylines with each of our six themes of interest. We represented the differences among percentage of primary themes in the Yahara stakeholder perspectives about change, Yahara 2070 representations of change, and 1997-2011 scenario-based studies with spider (or radar) plots. A total of 38 stakeholders described a primary change theme, each of the 4 Yahara 2070 scenarios had a primary theme, and the 124 global scenarios were each assigned a primary theme by Hunt et al. (2012).

\section{Understanding scenario development process and goals}

We evaluated what factors informed scenario creation through interviews with the development team to answer our second research question: How did Yahara 2070 scenario developers navigate multiple data sources, analytical modes, and project objectives and constraints to create scenarios of future change? Semistructured qualitative interviews were conducted with the five key members of the Yahara 2070 scenarios development team in the summer of 2014. These team members filled different roles in scenario creation, including gathering stakeholder input and writing the draft scenarios narratives; editing and writing the final narratives; advising on the plausible/provocative balance as related to socioeconomic, political, and agricultural and environmental components; developing future climate, hydrological, and agronomic models; and overseeing the project. These individual interviews focused on the steps and goals of the development process as each member conceived of them and on the factors that contributed to the relative weighting of stakeholder perceptions of change, archetypal change themes, and drivers used to satisfy scientific research questions. Interviews 
were transcribed and analyzed thematically, particularly focusing on influences and constraints in narrative development.

\section{RESULTS}

Our analysis of the Yahara 2070 scenario development process revealed inclusion of common change themes from the global scenarios literature, with significant tailoring to local issues. The Yahara 2070 scenarios incorporated five of the six archetypal themes of change, but the relative weight of these themes in Yahara 2070 narratives differed from local perspectives and a review of scenarios archetypes (Fig. 3). In this section, we describe how these differences came about: how the Yahara stakeholders perceived drivers of future change, how the final products of Yahara 2070 correspond with global change themes, and how scenario developers took stakeholder perspectives and other factors into account when developing four scenario narratives.

Fig. 3. Comparison of proportions of primary change themes for Yahara stakeholders, Yahara 2070 scenarios, and global scenarios review. Proportions (represented on a scale of 0-0.6) were calculated from the number of interviewees or scenarios describing a theme as primary over the total (38 interviewees, 4 Yahara 2070 scenarios, 124 global scenarios).

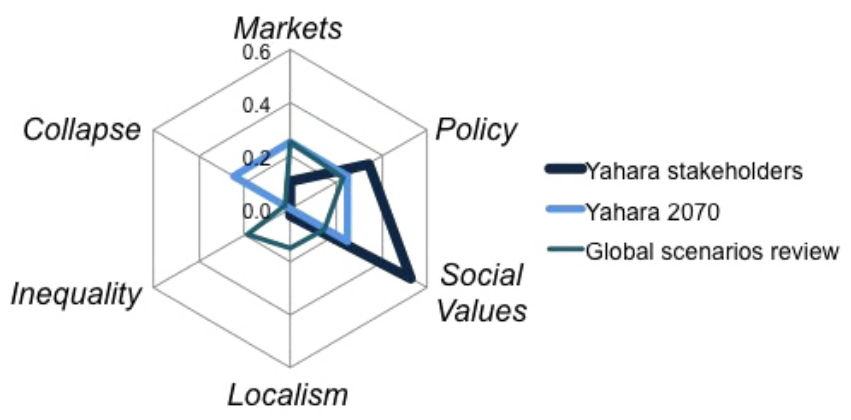

Stakeholder perceptions of future change

Themes of change associated with Markets, Policy, and Social Values were the most frequently mentioned in response to the question "Who or what will be most influential in determining the future?" Although both the Policy and Social Values themes were mentioned almost an equal number of times, Social Values was rated as the primary change theme more often than Policy. In addition, although the Markets theme was mentioned frequently (62\% as often as Social Values), it was the primary theme for very few respondents $(20 \%$ as many as for Social Values). It is important to note that a number of drivers were used to describe change across multiple themes; for instance, technology was conceived as a driver in Markets and Policy themes, whereas extreme climate change was described as a catalyst across several themes.

Figure 4 shows summary statistics of the weights for each change theme and describes the frequency of each theme overall and the frequency of themes that were weighted as a 3 in interviews. When comparing the weights of the four most frequently mentioned themes (Markets, Policy, Social Values, Collapse), Markets and Social Values were weighted significantly higher than Collapse at an alpha level of 0.05 (Table 3). Policy was higher than Collapse, but only marginally significant at the 0.1 level. Comparisons with Localism and Inequality were not computed because of the small sample sizes. There was no significant difference in the mean weightings of Markets, Policy, and Social Values.

Fig. 4. Summary statistics for each change theme from Yahara stakeholder interviews $(n=50)$. Each bar's height represents total mentions by stakeholders, with primary mentions in lighter gray, and each bar's width represents the theme's median weight on a scale from 1 to 3 .

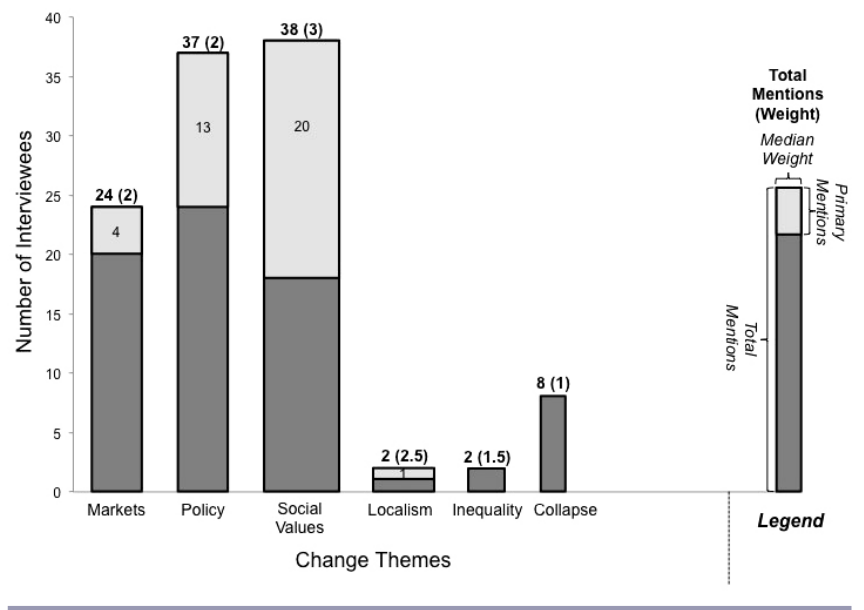

Table 3. Wilcoxon signed-rank tests comparing differences among change theme weights from Yahara stakeholder interviews.

\begin{tabular}{ccccc}
\hline \hline Change theme 1 & Change theme 2 & $\mathrm{n}$ & Z value & P value \\
\hline Markets & Policy & 21 & .475 & .635 \\
& Social Values & 16 & -1.12 & .262 \\
Policy & Collapse & 7 & 2.00 & $.0455^{* *}$ \\
& Social Values & 25 & -1.02 & .307 \\
Social Values & Collapse & 5 & 1.71 & $.0881^{*}$ \\
& Collapse & 8 & 2.00 & $.0455^{* *}$ \\
\hline
\end{tabular}

$* \mathrm{p}<.10 ; * * \mathrm{p}<.05 ; * * * \mathrm{p}<.01$.

We found that gender and affiliations had some influence on themes interviewees discussed. There was a statistically significant difference between men and women with respect to mentions of Collapse. Six women, or $35 \%$, discussed Collapse in their responses, whereas only 3 men, or $9 \%$, did so: $\chi^{2}(1,49)=3.87$, p $=.049$. Weights for other themes did not differ by gender. When respondents were grouped by whether they had an affiliation with agriculture, Localism was mentioned significantly more often by agricultural versus nonagricultural interviewees: $\chi^{2}(1,50)=9.49$, $\mathrm{p}=.002$. The only respondents who mentioned Localism were affiliated with local sustainable agriculture organizations rather than conventional agriculture. These interviewees had better experiences in their current work with flexible, locally led (rather than top-down) programming, so they emphasized local autonomy, saying of future change: "It's gotta be locally led" and "Don't hogtie us to the rules and the tools that are there; let us come up with the new tools that are needed."

Yahara 2070 scenarios and themes of change

We next analyzed how global archetypes were represented in the Yahara 2070 project's written scenario narratives (Fig. 2). This section describes the ways in which themes of change from the 
scenarios literature were integrated into narratives. Table 2 lists the primary theme associated with each Yahara 2070 scenario. Yahara 2070 devoted one scenario to Collapse (Abandonment and Renewal) and one scenario to a Social Values shift (Connected Communities). This differed from Yahara stakeholders' perception of change; overall interviewees weighted a Social Values shift more highly than societal Collapse. Policy and Markets themes played significant roles in future change, as they were portrayed in two Yahara 2070 scenario narratives, Accelerated Innovation and Nested Watersheds.

\section{Abandonment and Renewal}

In this scenario, climate change is worse than expected and society is unprepared, leaving the watershed with a much smaller population in 2070, with societal focus on survival and resilience. This scenario has an Abandonment phase and a Renewal phase. The Collapse theme characterizes the Abandonment phase. An environmental disaster occurs as a result of failure to adapt social and governmental institutions. The second phase, Renewal, depicts fragmented, self-sufficient, and highly dense living settlements aligned with the Localism theme. Governance is small scale and decentralized, and many communities are completely autonomous.

\section{Accelerated Innovation}

In this scenario, national leaders invest heavily in technology in response to environmental crises, creating a highly engineered landscape. The storyline presents rapid development of technology funded by national, state, and local government (Policy) and private companies (Markets): "In all facets of society, technology is given precedence: the government provides seed money for research and development, [and] the private sector invests in innovation..." The scenario fits most closely with the Markets theme because "natural processes are valued economically and controlled by market mechanisms," and people are drawn to the watershed for jobs, as "entrepreneurs and businesses base their headquarters here."

\section{Connected Communities}

In this scenario, looming environmental crises incite a global movement to adopt sustainable values and behaviors. By 2070, the Yahara region is a mosaic of sustainable agricultural, urban, and natural areas. Here, Social Values is the change theme, as "the younger generations embrace community building and sustainability through grassroots action to get their voices heard. ... This values shift has also happened at a global scale." Global youth, disenchanted by political gridlock and dismayed by climate change impacts, organize effectively to create a sustainable, values-driven society referred to as the Great Transition. By 2070, "connectivity, community, and environmental sustainability" are the new norm.

\section{Nested Watersheds}

In this scenario, climate change is worse than expected and the nation faces a freshwater crisis. Government-led change results in a national reorganization of freshwater management with units at the watershed scale. Change here is most influenced by Policy. Congress passes the Water Security Act of 2040, creating a new water governance framework, and giving authority to local governments to tailor federal policies to specific watersheds. So- called Watershed Management Authorities have the power to incentivize or regulate landowners and water users in their respective regions "to maintain, improve, and distribute freshwater."

\section{Yahara 2070 scenario developers' perspectives}

The Yahara 2070 scenario developers produced the four narratives described above, painting different pictures of how change, driven by local and global forces, might occur in the Yahara Watershed. Collectively, the scenarios development team described the overall approach as tailoring themes of change from the scenarios literature to the Yahara watershed. Stakeholder interview data were used to incorporate local perspectives on social values and processes of transformation into the narratives, increasing scenario relevance and plausibility for regional residents. Developers also needed to ensure that the final scenarios would support the desire for divergent social storylines for outreach goals and a variety of ecological trajectories with which to push the boundaries of quantitative modeling. Modeling of watershed processes was intentionally planned to take place after the four narratives were developed, so analyses could draw on distinct pathways of change.

Stakeholder input was used in two primary ways for scenario construction: to gather creative ideas about the future and to gauge the range of environmental and social values represented in the region. The developers then wrote scenarios that incorporated ideas from interviewees and included both dominant and under-represented values. One member of the scenarios development team explained, "We purposely designed the [stakeholder] interviews to be very open-ended... with the goal of getting really creative ideas." Another, explaining how social values were incorporated into the scenarios, said "we tried to write the stories so [stakeholder] values, or the opposite of those values, showed up in the scenarios. This addressed the need for the scenarios to evoke emotion, and resonate or conflict with the values stakeholders had identified." To create divergent storylines that would prompt creative and thoughtful conversations among watershed residents, the developers wanted to avoid any one scenario that a particular group of people would identify as a "utopia scenario."

To complement regional perspectives that ensured scenario relevance and plausibility and push the stories into more provocative territory, the development team drew on themes and ideas from previous regional and global scenarios projects, including personal experience working on the Millennium Ecosystem Assessment. For example, technology-driven and collapse narratives, which were used in the Millennium Ecosystem Assessment, influenced the Yahara 2070 developers. Scenario developers acknowledged myriad other sources of inspiration, including science fiction and national and international news stories, to come up with such events as a toxic algae-induced environmental disaster that forces human migration away from the watershed in the Abandonment and Renewal scenario. These innovative storylines pushed modelers to problem-solve and expand their capacity: "Modeling needs a challenge, like any discipline, to do new things, and these scenarios could challenge modeling capacity in new ways." For example, one of the scenario narratives described more frequent but unpredictable large storm 
events. This led the modelers to create simulated daily time steps for weather, consistent with each scenario storyline, and consistent with International Panel on Climate Change climate projections.

\section{DISCUSSION}

Scenarios of future social and ecological change are increasingly used to help societies grapple with how to fulfill diverse human needs sustainably without compromising ecosystems (Kates and Parris 2003, Brewer 2007). Scenario developers commonly seek to integrate change themes from scenarios literature with local stakeholder perceptions (de Vries and Petersen 2009, Metzger et al. 2010). Based on analysis of one regional scenarios project, Yahara 2070, we found significant overlap but important differences in emphasis among local stakeholder perspectives, themes from global scenarios archetypes, and the Yahara 2070 scenario narratives.

Yahara stakeholders most emphasized Social Values as driving change, followed by economy (Markets) and government (Policy). In contrast, there was low emphasis on cataclysmic change, although women were more likely to cite this type of change than men. The Great Transitions archetype's themes, Social Values and Localism, present fairly hopeful visions for the power of human values and social movements (Raskin et al. 2002). Yahara stakeholders gave the most weight to this kind of change, citing communities, social values, and grassroots organizing more frequently than themes of change associated with Conventional or Barbarization scenario archetypes. The Yahara 2070 scenario Connected Communities is primarily driven by a Social Values shift. This suggests an understanding of sustainable change as raising fundamentally ethical questions concerning responsibility to future generations and nature's worth (Norton 2005, Miller et al. 2014). Conventional themes, on the other hand, assume the continuation of current trends without significant rupture in values, economies, or politics (Gallopín and Raskin 1998). The predominance of conventional narratives in our interviews may reflect stakeholders' familiarity with historical trajectories of path-dependent policies whose political "stickiness" makes it difficult to shift to a new trajectory (Levin et al. 2012).

The Barbarization archetype, with Inequality and Collapse themes, presents pessimistic visions of institutional failure and chaos. Dystopian future stories are popular in novels and television, but Yahara stakeholders rarely offered these types of breakdown narratives when they described what they see as influential determinants of the future. This failure to imagine drastic changes to institutions that are familiar fits with research on psychological distance; threats that seem more distant from an individual (i.e., threats that have occurred far in the past, to social "others," or in geographically distance places) are less concerning and less likely to come to mind (Liberman et al. 2007, Liberman and Trope 2008). Hunt et al. (2012) and Raskin (2005) point out that Barbarization narratives are also less common in the global scenarios literature. Although these narratives have the potential to repel stakeholders who dismiss doomsday warnings, they can provide a useful and provocative contrast to other storylines, and may create the most unexpected future outcomes of any of the archetypes. Numerous scenarios scholars (e.g., Berkhout et al. 2002, van Notten et al. 2005) contend that qualitative scenario narratives that forecast both gradual and sudden social change are needed to take into account the surprises and discontinuities that are normal features of past and future trajectories of human civilization. For this reason, the Yahara 2070 scenario Abandonment and Renewal depicts societal and institutional collapse, with significant impacts on both social and environmental variables. It is important to recognize, however, that discontinuities and surprise can result from types of change associated with other archetypes; global and local markets and governments, for instance, can go through rapid and unexpected changes that may disrupt social-ecological systems with as much or greater force than Barbarization themes. There are also other classifications of scenario narratives that, if used, could change the analysis of scenarios' and stakeholders' narratives of change. For example, Van Vuuren et al. (2012) classify themes similar to Inequality and Collapse under a "regional competition/regional markets" category, which is decidedly less extreme than the Barbarization archetype.

We expected certain characteristics of stakeholders to influence their conceptions of how change occurs. Two characteristics emerged as the most statistically and socially significant: gender and agricultural affiliation. First, among interviewees, women were more likely to cite Collapse narratives than men. This result is consistent with our expectations, given literature suggesting that women perceive environmental and other risks as more worrisome or problematic than men (Slovic 1999, Loewenstein et al. 2001, Sundblad et al. 2007). Second, those respondents affiliated with local, sustainable agriculture were more likely to cite Localism as an important change theme. This difference makes sense given that the sustainable agriculture community in the United States tends to emphasize local, grassroots effort in contrast to the national policies and markets that drive mainstream American agriculture (DuPuis and Goodman 2005). These findings speak to the importance of including a variety of stakeholders in the participatory scenario development process. By inviting perspectives from both men and women, as well as representatives across major sectoral divisions in the region, scenario developers ensure more diversity of opinion regarding how change might occur (Metzger et al. 2010).

Yahara 2070 narratives were made public in May 2014. Although modeling and outreach are ongoing at the time of this writing, the scenarios have resulted in a number of positive outcomes, including innovations in models such as Agro-IBIS, creation of community discussion groups, and collaboration on a public television special. Public comments to the scenario development team have covered a range of topics, but one consistent theme is the plausibility of the narratives; people think the scenarios either go too far or not far enough in telling creative stories about the future. The inclusion of both plausibility and provocativeness as development goals created the potential to push creativity in storytelling while staying relevant to the geographic and social context (Peterson et al. 2003, Wright 2010). In a project like Yahara 2070, in which stakeholders inform but do not decide on scenario narratives, the development team faces an important decision about how much to deviate from locally accepted themes. The potential benefits of expanding beyond common local views include connecting with themes important in other places and times around the world, and suggesting ideas for transformational change that may advance public discourse as well as quantitative modeling. The Yahara 2070 scenario with the most dramatic and 
negative social changes, Abandonment and Renewal, was driven by themes not reflected in stakeholder interviews. However, the story represents a potential ecological and social pathway that some local and global observers fear may occur without greater attention to climate change, pollution, and resource overuse. Furthermore, the process of modeling dramatic transformation provides a useful contrast to other scenarios that represent slower changes, and in fact the end ecological result, lakes free of algae and rich in biodiversity, is aligned with what many stakeholders currently desire. However, it is important to recognize that by presenting a scenario that is largely seen as undesirable, developers face the challenge of maintaining an exploratory rather than normative scenario development approach (Oteros-Rozas et al. 2015).

We therefore recommend transparency in the process by which themes of change are decided upon in a scenarios project so that stakeholders and other researchers are clear about the overlap and divergence between local perspectives, global archetypes, and other influences on scenario development. Although there are numerous guides to scenario methods, particularly for business applications (e.g., Van der Heijden 2011), it remains a challenge to record explicit methods for projects that blend scientific research and creative storytelling. Some work, however, has attempted to make the creative process more transparent. For example, Van Vliet et al. (2012) developed a method to measure the creativity of storylines using indicators of novelty, fluency, and elaboration. We suggest that open-book approaches to scenario development may improve the relevance, and potentially the outcomes, of scenario-building and outreach processes. A transparent project would document and narrate the development process in a variety of academic and nonacademic venues such as articles, workshops, and blog posts, explicitly highlighting sources of information and inspiration, as well as scientific and logistical constraints.

\section{CONCLUSION}

Scientists, planners, and policy makers must critically engage with the question of how to incorporate local perceptions and established representations of change in conversations about the future. Scenario development commonly relies on multiple sources of inspiration, but most scenario projects do not compare stakeholder perspectives, scenarios literature, and the scenario narratives they develop. Scenario developers may rely on stakeholder groups to edit out scenarios considered "overly provocative," but this can limit the range of alternatives to more predictable, rather than transformative, changes. In Yahara 2070, the goal of developing provocative but plausible scenarios led to narratives of the future that do not perfectly match stakeholder ideas, but that do emphasize unpredictable shifts and consequences for social and environmental futures.

Responses to this article can be read online at: http://www.ecologyandsociety.org/issues/responses. $\mathrm{php} / 8384$

\section{Acknowledgments: \\ We thank Jenny Seifert and Elizabeth Katt-Reinders for conducting interviews, organizing workshops, and writing the Yahara2070}

narratives, and John Miller of GrayJay graphics for creating the scenario illustrations. A big thanks to all participants in Yahara 2070 interviews and workshops. We appreciate the valuable comments of two anonymous reviewers on earlier versions of this article. This research was supported by the Water Sustainability and Climate project (DEB-1038759) and the North Temperate Lakes Long-Term Ecological Research program (DEB-0832652) of the National Science Foundation.

\section{LITERATURE CITED}

Alcamo, J. 2008. The SAS approach: combining qualitative and quantitative knowledge in environmental scenarios. Pages 123-150 in J. Alcamo, editor. Environmental futures: the practice of environmental scenario analysis. Elsevier, Amsterdam, The Netherlands. http://dx.doi.org/10.1016/s1574-101x(08)00406-7

Berkhout, F., J. Hertin, and A. Jordan. 2002. Socio-economic futures in climate change impact assessment: using scenarios as "learning machines." Global Environmental Change 12(2):83-95. http://dx.doi.org/10.1016/s0959-3780(02)00006-7

Biggs, R., C. Raudsepp-Hearne, C. Atkinson-Palombo, E. Bohensky, E. Boyd, G. Cundill, H. Fox, S. Ingram, K. Kok, S. Spehar, M. Tengö, D. Timmer, and M. Zurek. 2007. Linking futures across scales: a dialog on multiscale scenarios. Ecology and Society 12(1):17. [online] URL: http://www.ecologyandsociety. org/vol12/iss1/art17/

Bohensky, E. L., B. Reyers, and A. S. Van Jaarsveld. 2006. Future ecosystem services in a Southern African river basin: a scenario planning approach to uncertainty. Conservation Biology 20 (4):1051-1061. http://dx.doi.org/10.1111/j.1523-1739.2006.00475. $\underline{\mathrm{X}}$

Bradley, N. L., A. C. Leopold, J. Ross, and W. Huffaker. 1999. Phenological changes reflect climate change in Wisconsin. Proceedings of the National Academy of Sciences of the United States of America 96 (17):9701-9704. http://dx.doi.org/10.1073/ pnas.96.17.9701

Brewer, G. D. 2007. Inventing the future: scenarios, imagination, mastery and control. Sustainability Science 2(2):159-177. http:// dx.doi.org/10.1007/s11625-007-0028-7

Carpenter, S. R., E. M. Bennett, and G. D. Peterson. 2006. Scenarios for ecosystem services: an overview. Ecology and Society 11(1):29. [online] URL: http://www.ecologyandsociety. org/vol11/iss1/art29/

Carpenter, S. R., B. J. Benson, R. Biggs, J. W. Chipman, J. A. Foley, S. A. Golding, R. B. Hammer, P. C. Hanson, P. T. J. Johnson, A. M. Kamarainen, et al. 2007. Understanding regional change: a comparison of two lake districts. Bioscience 57(4):323-335. http://dx.doi.org/10.1641/b570407

Carpenter, S. R., E. G. Booth, C. J. Kucharik, and R. C. Lathrop. $2015 b$. Extreme daily loads: role in annual phosphorus input to a north temperate lake. Aquatic Sciences 77(1):71-79. http://dx. doi.org/10.1007/s00027-014-0364-5

Carpenter, S. R., E. R. Booth, S. Gillon, C. J. Kucharik, S. Loheide, A. S. Mase, M. Motew, J. Qiu, A. R. Rissman, J. Seifert, E. Soylu, M. G. Turner, and C. B. Wardropper. 2015a. Plausible futures of a social-ecological system: Yahara watershed, 
Wisconsin, USA. Ecology and Society 20(2):10. http://dx.doi. org/10.5751\%2FES-07433-200210

Carpenter, S. R., and A. R. Rissman. 2012. Scenarios and decisionmaking for complex environmental systems. Pages 37-43 in D. N. Bengston, editor. Environmental futures research: experiences, approaches, and opportunities. Gen. Tech. Rep. NRSP-107. U.S. Department of Agriculture, Forest Service, Northern Research Station, Newtown Square, Pennsylvania, USA.

Chermack, T. J., S. A. Lynham, and W. E. A. Ruona. 2001. A review of scenario planning literature. Futures Research Quarterly 17(2):7-31.

de Vries, B. J. M., and A. C. Petersen. 2009. Conceptualizing sustainable development: an assessment methodology connecting values, knowledge, worldviews and scenarios. Ecological Economics 68(4):1006-1019. http://dx.doi.org/10.1016/j. ecolecon.2008.11.015

DuPuis, E. M., and D. Goodman. 2005. Should we go "home" to eat?: toward a reflexive politics of localism. Journal of Rural Studies 21(3):359-371. http://dx.doi.org/10.1016/j.jrurstud.2005.05.011

Enfors, E. I., L. J. Gordon, G. D. Peterson, and D. Bossio. 2008. Making investments in dryland development work: participatory scenario planning in the Makanya catchment, Tanzania. Ecology and Society 13(2):42. [online] URL: http://www.ecologyandsociety. org/vol13/iss2/art42/

Evans, K., S. J. Velarde, R. Prieto, S. N. Rao, S. Sertzen, K. Dávila, P. Cronkleton, and W. de Jong. 2006. Field guide to the future: four ways for communities to think ahead. Center for International Forestry Research, ASB, and World Agroforestry Centre, Nairobi, Kenya.

Gallopín, G. C., and P. Raskin. 1998. Windows on the future: global scenarios \& sustainability. Environment: Science and Policy for Sustainable Development 40(3):6-11. http://dx.doi. org/10.1080/00139159809603187

Garb, Y., S. Pulver, and S. D. VanDeveer. 2008. Scenarios in society, society in scenarios: toward a social scientific analysis of storyline-driven environmental modeling. Environmental Research Letters 3(4):45015. http://dx.doi.org/10.1088/1748-9326/3/4/045015

Gibson, C. C., E. Ostrom, and T.-K. Ahn. 2000. The concept of scale and the human dimensions of global change: a survey. Ecological Economics 32(2):217-239. http://dx.doi.org/10.1016/ $\underline{\text { s0921-8009(99)00092-0 }}$

Gillon, S., E. G. Booth, and A. R. Rissman. 2016. Shifting drivers and static baselines in environmental governance: challenges for improving and proving water quality outcomes. Regional Environmental Change 16(3):759-775. http://dx.doi.org/10.1007/ $\underline{\text { s10113-015-0787-0 }}$

Huberman, M., and M. B. Miles. 2002. The qualitative researcher's companion. Sage, Thousand Oaks, California, USA.

Hunt, D. V. L., D. R. Lombardi, S. Atkinson, A. R. G. Barber, M. Barnes, C. T. Boyko, J. Brown, J. Bryson, D. Butler, S. Caputo, et al. 2012. Scenario archetypes: converging rather than diverging themes. Sustainability 4(4):740-772. http://dx.doi.org/10.3390/ $\underline{\mathrm{su} 4040740}$
Jacobs, K., L. Lebel, J. Buizer, L. Addams, P. Matson, E. McCullough, P. Garden, G. Saliba, and T. Finan. 2010. Linking knowledge with action in the pursuit of sustainable waterresources management. Proceedings of the National Academy of Sciences of the United States of America 200813125.

Kates, R. W., and T. M. Parris. 2003. Long-term trends and a sustainability transition. Proceedings of the National Academy of Sciences of the United States of America 100(14):8062-8067. http://dx.doi.org/10.1073/pnas.1231331100

Kepner, W. G., M. M. Ramsey, E. S. Brown, M. E. Jarchow, K. J. M. Dickinson, and A. F. Mark. 2012. Hydrologic futures: using scenario analysis to evaluate impacts of forecasted land use change on hydrologic services. Ecosphere 3(7):69. http://dx.doi. org/10.1890/es11-00367.1

Kok, K., R. Biggs, and M. Zurek. 2007. Methods for developing multiscale participatory scenarios: insights from southern Africa and Europe. Ecology and Society 12(1):8. [online] URL: http:// www.ecologyandsociety.org/vol12/iss1/art8/

Kok, K., and M. van Vliet. 2011. Using a participatory scenario development toolbox: added values and impact on quality of scenarios. Journal of Water and Climate Change 2(2-3):87-105. http://dx.doi.org/10.2166/wcc.2011.032

Kok, K., M. van Vliet, I. Bärlund, A. Dubel, and J. Sendzimir. 2011. Combining participative backcasting and exploratory scenario development: experiences from the SCENES project. Technological Forecasting and Social Change 78(5):835-851. http://dx.doi.org/10.1016/j.techfore.2011.01.004

Lathrop, R. C. 2007. Perspectives on the eutrophication of the Yahara lakes. Lake and Reservoir Management 23(4):345-365. http://dx.doi.org/10.1080/07438140709354023

Lempert, R. 2013. Scenarios that illuminate vulnerabilities and robust responses. Climatic Change 117(4):627-646. http://dx.doi. org/10.1007/s10584-012-0574-6

Levin, K., B. Cashore, S. Bernstein, and G. Auld. 2012. Overcoming the tragedy of super wicked problems: constraining our future selves to ameliorate global climate change. Policy Sciences 45(2):123-152. http://dx.doi.org/10.1007/s11077-012-9151-0

Liberman, N., and Y. Trope. 2008. The psychology of transcending the here and now. Science 322(5905):1201-1205. http://dx.doi.org/10.1126/science.1161958

Liberman, N., Y. Trope, and E. Stephan. 2007. Psychological distance. Pages 353-383 in A. W. Kruglanksi and E. T. Higgins, editors. Social psychology: handbook of basic principles. Guilford, New York, New York, USA.

Loewenstein, G. F., E. U. Weber, C. K. Hsee, and N. Welch. 2001. Risk as feelings. Psychological Bulletin 127(2):267. http://dx.doi. org/10.1037/0033-2909.127.2.267

March, H., O. Therond, and D. Leenhardt. 2012. Water futures: reviewing water-scenario analyses through an original interpretative framework. Ecological Economics 82:126-137. http://dx.doi.org/10.1016/j.ecolecon.2012.07.006

Merriam-Webster. 2004. Merriam-Webster's collegiate dictionary. 11th edition. Merriam-Webster, Springfield, Massachusetts, USA. 
Metzger, M. J., M. D. A. Rounsevell, H. Van den Heiligenberg, M. Pérez-Soba, and P. Soto Hardiman. 2010. How personal judgment influences scenario development: an example for future rural development in Europe. Ecology and Society 15(2):5. [online] URL: http://www.ecologyandsociety.org/vol15/iss2/art5/

Millennium Ecosystem Assessment. 2003. People and ecosystems: a framework for assessment and action. Island Press, Washington, D.C., USA.

Miller, T. R., A. Wiek, D. Sarewitz, J. Robinson, L. Olsson, D. Kriebel, and D. Loorbach. 2014. The future of sustainability science: a solutions-oriented research agenda. Sustainability Science 9(2):239-246. http://dx.doi.org/10.1007/s11625-013-0224-6

Millett, S. M. 2003. The future of scenarios: challenges and opportunities. Strategy \& Leadership 31(2):16-24. http://dx.doi. org/10.1108/10878570310698089

Motew, M. M., and C. J. Kucharik. 2013. Climate-induced changes in biome distribution, NPP, and hydrology in the Upper Midwest U.S.: a case study for potential vegetation. Journal of Geophysical Research: Biogeosciences 118(1):248-264. http://dx. doi.org/10.1002/jgrg.20025

National Park Service. 2013. Using scenarios to explore climate change: a handbook for practitioners. National Park Service, Fort Collins, Colorado, USA.

Netherlands Environmental Assessment Agency (PBL). 2004. Quality and the future: first sustainability outlook. PBL, Bilthoven, Netherlands.

Norton, B. G. 2005. Sustainability: a philosophy of adaptive ecosystem management. University of Chicago Press, Chicago, Illinois, USA. http://dx.doi.org/10.7208/chicago/9780226595221.001.0001

O’Neill, K. M. 2007. Can watershed management unite town and country? Society \& Natural Resources 18(3):241-253.

Oteros-Rozas, E., B. Martín-López, T. M. Daw, E. L. Bohensky, J. R. A. Butler, R. Hill, J. Martin-Ortega, A. Quinlan, F. Ravera, I. Ruiz-Mallén, M. Thyresson, J. Mistry, I. Palomo, G. D. Peterson, T. Plieninger, K. A. Waylen, D. M. Beach, I. C. Bohnet, M. Hamann, J. Hanspach, K. Hubacek, S. Lavorel, and S. P. Vilardy. 2015. Participatory scenario planning in place-based social-ecological research: insights and experiences from 23 case studies. Ecology and Society 20(4):32. http://dx.doi.org/10.5751/ ES-07985-200432

Palacios-Agundez, I., I. Casado-Arzuaga, I. Madariaga, and M. Onaindia. 2013. The relevance of local participatory scenario planning for ecosystem management policies in the Basque Country, northern Spain. Ecology and Society 18(3):7. http://dx. doi.org/10.5751/ES-05619-180307

Palomo, I., B. Martín-López, C. López-Santiago, and C. Montes. 2011. Participatory scenario planning for protected areas management under the ecosystem services framework: the Doñana social-ecological system in southwestern Spain. Ecology and Society 16(1):23. [online] URL: http://www.ecologyandsociety. org/vol16/iss1/art23/

Patel, M., K. Kok, and D. S. Rothman. 2007. Participatory scenario construction in land use analysis: an insight into the experiences created by stakeholder involvement in the Northern
Mediterranean. Land Use Policy 24(3):546-561. http://dx.doi. org/10.1016/j.landusepol.2006.02.005

Peterson, G. D., G. S. Cumming, and S. R. Carpenter. 2003. Scenario planning: a tool for conservation in an uncertain world. Conservation Biology 17(2):358-366. http://dx.doi.org/10.1046/ j.1523-1739.2003.01491.x

Pulver, S., and S. D. VanDeveer. 2009. "Thinking about tomorrows": scenarios, global environmental politics, and social science scholarship. Global Environmental Politics 9(2):1-13. http://dx.doi.org/10.1162/glep.2009.9.2.1

Raskin, P. D. 2005. Global scenarios: background review for the Millennium Ecosystem Assessment. Ecosystems 8(2):133-142. http://dx.doi.org/10.1007/s10021-004-0074-2

Raskin, P., T. Banuri, G. Gallopin, P. Gutman, A. Hammond, R. Kates, and R. Swart. 2002. Great transition: the promise and lure of the times ahead. Stockholm Environment Institute, Boston, Massachusetts, USA.

Rissman, A. R., and S. Carpenter. 2015. Progress on nonpoint pollution: barriers and opportunities. Daedalus 144(3):35-47. http://dx.doi.org/10.1162/daed a 00340

Rounsevell, M. D. A., F. Ewert, I. Reginster, R. Leemans, and T. R. Carter. 2005. Future scenarios of European agricultural land use: II. Projecting changes in cropland and grassland. Agriculture, Ecosystems \& Environment 107(2):117-135. http://dx.doi. org/10.1016/j.agee.2004.12.002

Rounsevell, M. D. A., and M. J. Metzger. 2010. Developing qualitative scenario storylines for environmental change assessment. Climate Change 1(4):606-619. http://dx.doi. org/10.1002/wcc. 63

Schwartz, P. 1996. The art of the long view: paths to strategic insight for yourself and your company. Broadway Business, New York, New York, USA.

Slovic, P. 1999. Trust, emotion, sex, politics, and science: surveying the risk-assessment battlefield. Risk Analysis 19 (4):689-701. http://dx.doi.org/10.1111/j.1539-6924.1999.tb00439. $\underline{x}$

Smith, L. A. 2002. What might we learn from climate forecasts? Proceedings of the National Academy of Sciences of the United States of America 99(suppl 1):2487-2492. http://dx.doi. org/10.1073/pnas.012580599

Sundblad, E.-L., A. Biel, and T. Gärling. 2007. Cognitive and affective risk judgements related to climate change. Journal of Environmental Psychology 27(2):97-106. http://dx.doi.org/10.1016/ j.jenvp.2007.01.003

Van der Heijden, K. 2011. Scenarios: the art of strategic conversation. John Wiley \& Sons, Chichester, UK.

Van Huylenbroeck, G. 1995. Multicriteria analysis of the conflicts between rural development scenarios in the Gordon District, Scotland. Journal of Environmental Planning and Management 38 (3):393-408. http://dx.doi.org/10.1080/09640569512931

van Notten, P. W. F., A. M. Sleegers, and M. B. A. van Asselt. 2005. The future shocks: on discontinuity and scenario development. Technological Forecasting and Social Change 72 (2):175-194. http://dx.doi.org/10.1016/j.techfore.2003.12.003 
van Vliet, M., K. Kok, A. Veldkamp, and S. Sarkki. 2012. Structure in creativity: an exploratory study to analyse the effects of structuring tools on scenario workshop results. Futures 44 (8):746-760. http://dx.doi.org/10.1016/j.futures.2012.05.002

van Vuuren, D. P., M. T. J. Kok, B. Girod, P. L. Lucas, and B. de Vries. 2012. Scenarios in global environmental assessments: key characteristics and lessons for future use. Global Environmental Change 22(4):884-895. http://dx.doi.org/10.1016/j.gloenvcha.2012.06.001

Wack, P. 1985. Scenarios: shooting the rapids: how medium-term analysis illuminated the power of scenarios for shell management. Harvard Business Review 63(6):139-150.

Walker, B. H., L. H. Gunderson, A. P. Kinzig, C. Folke, S. R. Carpenter, and L. Schultz. 2006. A handful of heuristics and some propositions for understanding resilience in social-ecological systems. Ecology and Society 11(1):13. [online] URL: http://www. ecologyandsociety.org/vol11/iss1/art13/

Wardropper, C. B., C. Chang, and A. R. Rissman. 2015. Fragmented water quality governance: constraints to spatial targeting for nutrient reduction in a Midwestern USA watershed. Landscape and Urban Planning 137:64-75. http://dx.doi. org/10.1016/j.landurbplan.2014.12.011

Wiek, A., and D. Iwaniec. 2014. Quality criteria for visions and visioning in sustainability science. Sustainability Science 9 (4):497-512. http://dx.doi.org/10.1007/s11625-013-0208-6

Wright, E. O. 2010. Envisioning real utopias. Verso, London, UK.

Zurek, M. B., and T. Henrichs. 2007. Linking scenarios across geographical scales in international environmental assessments. Technological Forecasting and Social Change 74(8):1282-1295. http://dx.doi.org/10.1016/j.techfore.2006.11.005 